\title{
BATTERY SUPPLIER DEVELOPMENT FOR NEW ENERGY VEHICLES BY A PROBABILISTIC LINGUISTIC UTASTAR METHOD
}

\author{
Huchang LIAO $^{1 *}$, Zhihang LIU $^{2}$, Audrius BANAITIS ${ }^{3}$, \\ Edmundas Kazimieras ZAVADSKAS ${ }^{4}$, Xiang ZHOU ${ }^{5}$ \\ 1,2Business School, Sichuan University, Chengdu, China \\ ${ }^{3}$ Dept of Construction Management and Real Estate, Vilnius Gediminas Technical University, Vilnius, Lithuania \\ ${ }^{4}$ Institute of Sustainable Construction, Vilnius Gediminas Technical University, Vilnius, Lithuania \\ ${ }^{5}$ School of Finance, Anhui University of Finance and Economics, Bengbu, China
}

Submitted 19 April 2020; resubmitted 20 July 2020; accepted 24 August 2020;

first published online 10 May 2021

\begin{abstract}
New energy vehicles can improve the environmental pollution and thus benefit people's healthy life. As a core component of new energy vehicles, batteries play a crucial role in the performance of new energy vehicles. There are many factors to be considered when selecting the battery for a new energy vehicle, so it can be regarded as a MCDM problem. This study builds a useful model by combining the PLTS with the UTASTAR method. Firstly, to represent the uncertain and fuzzy information of experts, we use the PLTSs to accurately express the linguistic information of experts. Given that the weights of criteria are often different and there are some preferences for criteria among experts, we use the BWM to determine the weights of criteria, which can deal with hesitant information and make the result suitable for experts' preferences. The method proposed in this study can sort all alternatives based on a small amount of data. To show its applicability, we implement the method in the selection of new energy vehicle battery suppliers. Comparative analysis and discussions are made to verify the effectiveness of the method.
\end{abstract}

Keywords: new energy vehicle, battery supplier development, best-worst method, probabilistic linguistic term set, UTASTAR.

\section{Notations}

AHP - analytic hierarchy process;

BWM - best-worst method;

CSW - common set of weight;

DEA - data envelopment analysis;

DM - decision-maker;

LTS - linguistic term set;

MAUT - multi-attribute utility theory;

MCDM - multi-criteria decision-making;

MOORA - multi-objective optimization ratio analysis;

PCA - principal component analysis;

PL-UTASTAR - probabilistic linguistic UTASTAR;

PLTS - probabilistic LTS;

PROMETHEE - preference ranking organization method for enrichment of evaluation;

S-UTASTAR - spatial UTASTAR
UTA - utilities additives;

UTASTAR - an ordinal regression method for building additive value functions;

WASPAS - weighted aggregated sum product assessment.

\section{Introduction}

In recent years, the popularity of new energy vehicles has gradually increased under the guidance of government policy (Li, Jing 2019). More and more enterprises have designed and produced their own brands of new energy vehicles. New energy vehicles are composed of many parts such as on-board power supply, drive motor, control system, body, and site. Battery, as one of the most important components, often plays an important role in the overall performance of a vehicle (Chen et al. 2019). The components of new energy vehicles are mainly divided into two parts: self-production and procurement. The core tech-

${ }^{*}$ Corresponding author. E-mail: liaohuchang@163.com 
nology of the battery is in the hands of a few companies, which has the core competitiveness. Therefore, the battery is often purchased through bidding. In this regard, many factors need to be considered when choosing suppliers. In this sense, the battery supplier selection of new energy vehicles can be regarded as a MCDM problem.

The UTASTAR method, one of the most famous MCDM methods, builds models based on reference sets to deal with large-scale scheme sorting problem. It has been widely implemented in various decision scenarios. Jacquet-Lagreze and Siskos (1982) proposed the UTA method to evaluate the additional utility function of aggregate multi-variable, which is an effective method to estimate utilities by linear regression. Siskos and Yannacopoulos (1985) proposed the UTASTAR method based on the original UTA method to standardize the algorithm steps. Many scholars applied the UTASTAR method and its variations to various fields such as finance, materials, and tourism. In the battery supplier development process, procurement experts may have uncertainty and hesitancy in the evaluation process about the quality of candidates. Patiniotakis et al. (2011) proposed a fuzzy UTASTAR method, which combined the fuzzy information with the original UTASTAR method; however, the fuzzy information in their model was based on the classical fuzzy set, which could not represent the hesitant perceptions of experts over qualitative criteria. In this regard, linguistic terms and their extensions can be used to model the qualitative cognition of experts well (Liao et al. 2018). Especially, the PLTS proposed by Pang et al. (2016) has been regarded as a flexible technique to depict both fuzzy uncertainty and probabilistic uncertainty existed in comprehensive decision-making problems. Many achievements and fruitful results have been obtained over the past several years in terms of decision-making and information fusion (Liao et al. 2020; Mi et al. 2020). However, currently, as far as we know, there is no research focused on the UTASTAR method with probabilistic linguistic information. This consists the first research gap of this study.

In addition, the fuzzy UTASTAR method proposed by Patiniotakis et al. (2011) did not consider how to determine the weights of criteria. The weights of different criteria are always different for evaluators because of the different preferences toward different aspects. For example, when we go to a hospital for medical treatment, the effect of treatment is often the most concerned and thus the weight of the treatment effect should be higher compared with the price and distance. To determine the weights of criteria appropriately, many methods have been developed over the past years. Among them, the BWM is a recently proposed method, which can be regarded as a variation of the classical AHP (Saaty 1977) with less pairwise comparisons of each object with either the best or worst criterion (Rezaei 2015). The BWM and its various extensions from different perspectives have been implemented in different areas. A survey about the state of the art of the BWM can be found in research by Mi et al. (2019).
Based on the above analysis, we can find that the current research on the UTASTAR method cannot depict the hesitant linguistic information that may exist in practical decision-making problems. Thus, in this study, we aim to propose a PL-UTASTAR method integrated with the BWM and call it as the PL-UTASTAR method, which could not only deal with the probabilistic linguistic information but also consider the weights of criteria. We should note that the PLTS is a generalized form in terms of both fuzzy uncertainty and probabilistic uncertainty, and thus the proposed method is much more general than the existing UTASTAR variations. The creative notes of this study are as follow:

"» considering both the fuzzy uncertainty and probabilistic uncertainty of experts in the evaluation process, we represent the evaluations of experts by PLTSs; since the PLTS is a generalized form of both quantitative and qualitative fuzzy information, the proposed method is much more general than existing methods and experts can express their information more flexibly with PLTSs than other information representation forms;

"») we extend the traditional BWM to probabilistic linguistic context; given that the traditional UTASTAR method did not consider the weights of criteria, our method can determine the weights of criteria objectively;

"1) after incorporating the BWM with the PLUTASTAR method, we given the procedure of the PL-UTASTAR method and then implement it for the selection of new energy vehicle battery suppliers; some insights are given after data analysis.

The rest of this paper is composed as follows: in Section 1, the advances of the UTASTAR method, PLTS and BWM method are briefly reviewed. Section 2 proposes the PL-UTASTAR method and the detailed steps are listed. In Section 3, we select the most suitable new energy vehicle supplier by applying the PL-UTASTAR method. Some thoughts of this method and future research directions are put forward in Section 4. The paper is summarized last section.

\section{Literature review and preliminaries}

In this section, we review the UTASTAR method, PLTS and BWM for further presentation.

\subsection{Advances of the UTASTAR method}

Jacquet-Lagreze and Siskos (1982) proposed the UTA method to evaluate the utilities of alternatives based on the preference decomposition principle in MAUT. They used the linear programming technology to adjust the optimal additive nonlinear programming functions, matching the subjective evaluation of DMs. Many scholars applied the UTA method to different practical problems. For example, Athawale et al. (2011) used the UTA method in two real material selection cases. Walter and Pietrzak (2005) ap- 
plied the UTA method to the process of odour screening. Gruca and Sikora (2013) implemented the UTA method to the rule generation process and proved that the ordering calculated by this method is reliable. Grigoroudis and Zopounidis (2012) proposed a variable method based on the UTA method and considered the complexity of different working modes through multi-criteria analysis. Considering the variables of the original UTA method, the error of the model still needs to be reduced to improve the stability of the method.

Based on the original UTA method, the UTASTAR method was proposed (Siskos, Yannacopoulos 1985), which set the reference standard as the difference of marginal utilities between two consecutive values on each criterion. Using the additive formula, it is convenient to evaluate the utility values falling within this region. Based on the UTASTAR method, many scholars have done outreach and related research in the past. Patiniotakis et al. (2011) proposed the fuzzy UTASTAR method, which used fuzzy additive value functions to deal with both accurate and fuzzy evaluation information. Haider et al. (2015) used the fuzzy UTASTAR method in evaluating the water quality taking into account of five sustainability criteria and several sub-criteria to obtain the ranking of different water quality management schemes. Makui and Momeni (2012) used the CSW in DEA to explain DM's preference orderings in the UTASTAR method. The UTASTAR method was used to evaluate the utility function of investors in stock selection (Touni et al. 2019). Nikas et al. (2018) used the UTASTAR method in energy policymaking, which inferred local preferences from global preferences through preference decomposition. Demesouka et al. (2019) presented the S-UTASTAR, which was used for land-use suitability analysis based on multi-criteria spatial decision support systems. Zhang et al. (2020) proposed a prioritybased intuitionistic multiplicative UTASTAR method and used it in low carbon tourism destination selection. As we can see, the current researches on the UTASTAR method could not represent the hesitant perceptions of experts over qualitative criteria. In this regard, many experts' information cannot be expressed, and the model calculated from the reference set cannot deal with other data well. To bridge this challenge, we combine the PLTSs with the UTASTAR method to express the subjective expressions of qualitative criteria, which will improve the accuracy of the model with more information compared with the traditional method. Next, we will introduce the steps of the traditional UTASTAR method to facilitate further presentation.

The UTASTAR method aims to derive the additive value function from the reference set provided by a DM. Linear programming techniques are used to infer individual decision preferences in the form of utility functions, which again generate the ranking of schemes according to the distances to the reference set. The UTASTAR method can process the evaluation information of experts well through less data. The original UTASTAR method can be summarized in the following steps.

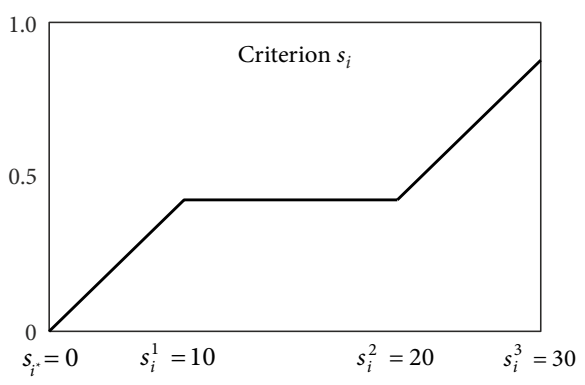

Figure 1. Example of piecewise linear utility function (Patiniotakis et al. 2011)

Step 1. Sorting the options in the reference set from the best to worst, i.e., $\beta_{1} \succ \beta_{2} \succ \ldots \succ \beta_{m}$. It is viable that some consecutive choices might be equal. The marginal utility function can be divided into several continuous parts and thus we assume that the function is piecewise linear (Figure 1). In addition, the score interval of the $i$ th criterion can be expressed as $\left[s_{i^{*}}, s_{i}^{*}\right]$, which can be divided into $\left(b_{i}-1\right)$ equal parts. The score of the end node can be expressed as $s_{i}^{j}$ for the $i$ th criterion and the $j$ th interval, where:

$$
s_{i}^{j}=s_{i^{*}}+\frac{j-1}{b_{i}-1} \cdot\left[s_{i}^{*}-s_{i^{*}}\right],
$$

for $i=1,2, \ldots, N$.

Step 2 . The marginal utility function of alternative $\beta$ on criterion $c_{i}$ can be expressed as:

$$
u_{i}\left[s_{i}(\beta)\right]=\sum_{x=1}^{k-1} \lambda_{i x}+\frac{s_{i}(\beta)-s_{i}^{j}}{s_{i}^{j+1}-s_{i}^{j}} \cdot \lambda_{i k}
$$

for $i=1,2, \ldots, N$, where: $\lambda_{i x}$ expresses the difference between the utility of two consecutive interval nodes.

Step 3. The global utility is calculated by the marginal utility:

$$
M[s(\beta)]=\sum_{i=1}^{n} u_{i}\left[s_{i}(\beta)\right]
$$

for $i=1,2, \ldots, N$.

The utility difference of successive opinions can be represented as:

$$
\begin{aligned}
& \Delta\left(\beta_{x}, \beta_{x+1}\right)=M\left[s\left(\beta_{x}\right)\right]-\varepsilon^{+}\left(\beta_{x}\right)+ \\
& \varepsilon^{-}\left(\beta_{x}\right)-M\left[s\left(\beta_{x+1}\right)\right]+\varepsilon^{+}\left(\beta_{x+1}\right)-\varepsilon^{-}\left(\beta_{x+1}\right),
\end{aligned}
$$

where: $\varepsilon^{+}(\beta), \varepsilon^{-}(\beta)$ represent the overestimation and underestimation, respectively.

Step 4. To minimize the errors of the whole model, it is necessary to minimize the combination of all the overestimations and underestimations. It also needs to satisfy the initial ordering given by the DM. In addition, the sum of all the difference between the utility of two consecutive interval nodes should be one. In this sense, the following linear programming can be established: 


$$
\begin{aligned}
& \min \tilde{G}=\sum_{x=1}^{m}\left(\varepsilon^{+}\left(\beta_{x}\right)+\varepsilon^{-}\left(\beta_{x}\right)\right) \\
& \text { s.t.: }\left\{\begin{array}{l}
\Delta\left(\beta_{x}, \beta_{x+1}\right) \geq \gamma, \text { if } \beta_{x} \succ \beta_{x+1}, \forall x ; \\
\Delta\left(\beta_{x}, \beta_{x+1}\right) \approx 0, \text { if } \beta_{x} \sim \beta_{x+1}, \forall x ; \\
\sum_{i=1}^{N} \sum_{j=1}^{b_{i}-1} \lambda_{i j}=1 ; \\
\lambda_{i j} \geq 0, \varepsilon^{+}\left(\beta_{x}\right) \geq 0, \varepsilon^{-}\left(\beta_{x}\right) \geq 0, \forall i, j, x .
\end{array}\right.
\end{aligned}
$$

By selecting the values of the paragraph points in sections, the utility function is used to calculate the values falling within the interval. More details about the UTASTAR method can be found in Patiniotakis et al. (2011) and Xiong, Cheng (2016).

\subsection{PLTS}

When we tolerate uncertainty or acknowledge the cost of precise numbers, linguistic variables have an advantage over precise numbers, especially for qualitative variables (Zadeh 1965, 1975, 2012). In addition, linguistic variables can represent numbers to some extent. Due to these advantages, many scholars have studied linguistic variables (Liao et al. 2018). To evaluate a linguistic variable, a LTS should be decided firstly as an assessment scale. There are two common LTSs $S_{1}=\left\{S_{\alpha} \mid \alpha=0,1, \ldots, 2 \cdot \tau\right\}$ and $S_{2}=\left\{S_{\alpha} \mid \alpha=-\tau, \ldots, 0, \ldots, \tau\right\}$, where $\tau$ is a positive integer. Both of them can be chosen according to the actual situation. In this paper, we take the second one as an illustration.

In some cases, linguistic variables cannot be accurately given by DMs. Additionally, there is even hesitation between different linguistic variables. For instance, an expert is $70 \%$ sure that the project is "good" and $30 \%$ sure "pretty good". To represent such kind of information, the concept of PLTS was proposed to express experts' evaluation information accurately (Pang et al. 2016).

Definition. Let $S=\left\{s_{-\tau}, \ldots, s_{0}, \ldots, s_{\tau}\right\}$ be an LTS (Pang et al. 2016). The PLTS can be expressed as:

$$
\begin{aligned}
& U(p)=\left\{U^{(v)}\left(p^{(v)}\right) \mid U^{(v)} \in S, p^{(v)} \geq 0,\right. \\
& \left.v=1,2, \ldots, \# U(p), \sum_{v=1}^{\# U(p)} p^{(v)} \leq 1\right\},
\end{aligned}
$$

where: $U^{(v)}\left(p^{(v)}\right)$ refers to the linguistic term $U^{(v)}$ with the probability $p^{(v)}$, and the number of all different linguistic terms is $\# U(p)$.

For a PLTS with $\sum_{v=1}^{\# U(p)} p^{(v)}<1$, its normalized form can be expressed as (Pang et al. 2016):

$$
\dot{U}(p)=\left\{U^{(v)}\left(\dot{p}^{(v)}\right) \mid v=1,2, \ldots, \# U_{1}(p)\right\},
$$

where:

$$
\dot{p}^{(v)}=\frac{p^{(v)}}{\sum_{v}^{\# U(p)} p^{(v)}}
$$

for all $v=1,2, \ldots, \# U(p)$.

For the normalized PLTS $U(p)$ with $\alpha^{(v)}$ being the subscript of the LTS, the score function is (Wu et al. 2018):

$$
E(U(p))=\frac{\sum_{v=1}^{\# U(p)}\left(\frac{\tau+\alpha^{(v)}}{2 \cdot \tau} \cdot p^{(v)}\right)}{\sum_{v=1}^{\# U(p)} p^{(v)}} .
$$

According to the score function, the variance of $U(p)$ is:

$$
\sigma(U(p))=\left(\frac{\sum_{v=1}^{\# U(p)}\left(\left(\frac{\tau+\alpha^{(v)}}{2 \cdot \tau}-E(U(p))\right)^{2} \cdot p^{(v)}\right)}{\sum_{v=1}^{\# U(p)} p^{(v)}}\right)^{\frac{1}{2}}
$$

\subsection{BWM}

To determine the weights of criteria, scholars have done a lot of research, among which the AHP (Saaty 1977) is a classical method that adopts the idea of pairwise comparisons over the selection criteria. The AHP was used in supplier selection by Hruška et al. (2014). To deal with the uncertainty, Stević et al. (2019) used the fuzzy AHP to determine the importance of different standards for suppliers. Beiragh et al. (2020) put forward a method of sustainable performance evaluation from qualitative and quantitative perspectives, using the AHP to give subjective weights to the data, and then using the PCA to give objective weights to the data to reduce the number of indicators. Compared with the AHP, the BWM (Rezaei 2015) can greatly reduce the number of pairwise comparisons. Since the BWM was proposed, many scholars have made further research on this method. Mi et al. (2019) made a literature review on the BWM method. Many scholars applied the BWM to practical scenarios. Van de Kaa et al. (2020) used the BWM in the value ranking of ethical and moral issues of new technology, and ranked smart meters through three dimensions of social politics, market and family. Ishizaka and Resce (2021) proposed the BestWorst-PROMETHEE to avoid the problem of ranking inversion, and used the proposed method to rank schools in the program for international student assessment. Asadabadi et al. (2020) proposed a fuzzy inference system to evaluate fuzzy items and used the BWM method in the ordering process against the delivered products. In this paper, we use the BWM to determine the weights of criteria, which can make the model get an accurate ordering. The steps of the original BWM are shown as follows. 
Step 1. Establish decision criteria for alternatives. The identification of evaluation criteria for alternatives is essential and serves as the basis for evaluation. A set of decision criteria $C=\left\{c_{1}, c_{2}, \ldots, c_{n}\right\}$ are supposed to be provided by DMs firstly.

Step 2. Identify the best criteria $c_{b}$ and the worst criteria $c_{w}$ from the set $C=\left\{c_{1}, c_{2}, \ldots, c_{n}\right\}$.

Step 3. Compare the best criteria $c_{b}$ with all the other criteria from $C$. The DMs could express their preferences by 1 to 9 , which could be expressed as $P_{B}=\left\{p_{B 1}, p_{B 2}, \ldots, p_{B n}\right\}$.

Step 4. Compare all the other criteria from $C$ with $c_{w}$. The DM could express their preferences by 1 to 9 , which could be expressed as $P_{W}=\left\{p_{1 W}, p_{2 W}, \ldots, p_{n W}\right\}^{T}$.

Step 5. According to the above preferences, the optimal weights of criteria are calculated and expressed as $\left(w_{1}^{\#}, w_{2}^{\#}, \ldots, w_{n}^{\#}\right)$. To get the optimal weights of criteria, for each pair of $w_{B} / w_{i}$ and $w_{i} / w_{W}$, they should satisfy $\frac{w_{B}}{w_{i}}=p_{B i}$ and $\frac{w_{i}}{w_{W}}=p_{i W}$. We aim to minimize the $w_{i}$
maximum of the absolute value difference $\left|\frac{w_{b}}{w_{i}}-p_{B i}\right|$ and $\left|\frac{w_{i}}{w_{w}}-p_{i W}\right|$. In addition, the non-negative and additive properties must be satisfied. Thus, the following model is established:

$$
\begin{aligned}
& \min \max _{i}\left\{\left|\frac{w_{b}}{w_{i}}-p_{B i}\right|,\left|\frac{w_{i}}{w_{w}}-p_{i W}\right|\right\} \\
& \text { s.t.: }\left\{\begin{array}{l}
\sum_{i} w_{i}=1 ; \\
w_{i} \geq 0, \text { for all } i .
\end{array}\right.
\end{aligned}
$$

The above programming can be translated into the following model:

$$
\begin{aligned}
& \min \psi \\
& \text { s.t.: }\left\{\begin{array}{l}
\left|\frac{w_{b}}{w_{i}}-p_{B i}\right| \leq \psi, \text { for all } i ; \\
\left|\frac{w_{i}}{w_{w}}-p_{i W}\right| \leq \psi, \text { for all } i ; \\
\sum_{i} w_{i}=1 ; \\
w_{i} \geq 0, \text { for all } i .
\end{array}\right.
\end{aligned}
$$

Solving this model, we can get the optimal weight vec$\operatorname{tor}\left(\tilde{w}_{1}^{*}, \tilde{w}_{2}^{*}, \tilde{w}_{3}^{*}, \ldots, \tilde{w}_{n}^{*}\right)^{T}$.

\section{The PL-UTASTAR method}

Sometimes, experts may not provide accurate evaluations and often hesitate between two or more standards. Such uncertainty would lead to the loss of information and inaccurate evaluations. Because the importance of criteria is different, we need to consider the weights of criteria in evaluation. In this sense, we propose the PL-UTASTAR

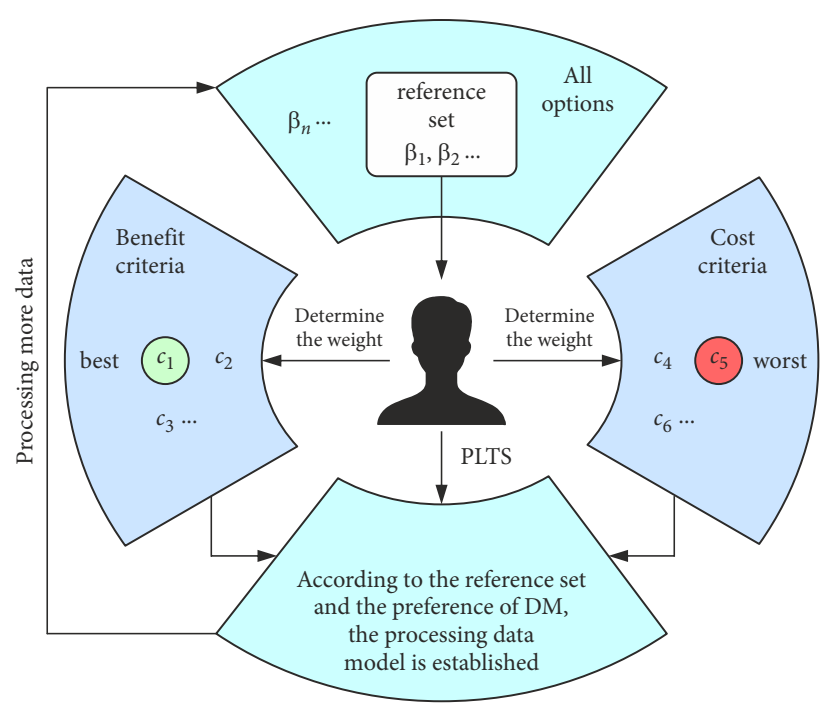

Figure 2. The idea of the PL-UTASTAR method

method, which conforms to the linguistic expression habits of experts and considers the influence brought by the weights of criteria. DMs can evaluate different alternatives according to their preferences under different criteria. The evaluation information provided by experts is expressed by PLTSs and the output is crisp numbers. Compared with the original UTASTAR method, the PL-UTASTAR method improves the accuracy of expert evaluations and collects information more comprehensively. The idea of the PL-UTASTAR method is demonstrated in Figure 2.

\subsection{Steps of the PL-UTASTAR method}

The steps of the PL-UTASTAR method are as follows (Figure 3).

Step 1. Determine the set of evaluation criteria $C=\left\{c_{1}, c_{2}, \ldots, c_{n}\right\}$ and the weights of criteria are supposed to be calculated by the BWM method.

Step 2. Sorting the options in the reference set from the best to the worst, i.e., $\beta_{1} \succ \beta_{2} \succ \ldots \succ \beta_{m}$. All the opinions in the reference set are expressed in PLTSs by the $\mathrm{DM}$ and the set of linguistic terms are sorted in ascending order. It is viable that some consecutive choices are equal, but too many of these situations will affect the accuracy of the result.

Step 3. Before expressing the global utility of alternatives, the marginal utility functions of criteria are expressed by:

$$
\begin{aligned}
& \tilde{u}_{i}\left[s_{i}(\beta)\right]=\sum_{x=1}^{k-1} \tilde{\lambda}_{i x}+\frac{\tilde{s}_{i}(\beta)-s_{i}^{j}}{s_{i}^{j+1}-s_{i}^{j}} \cdot \tilde{\lambda}_{i k}, \\
& \forall i=1,2, \ldots, N .
\end{aligned}
$$

The global utility is calculated by the marginal utilities and their corresponding weights:

$$
M[s(\beta)]=w_{i} \cdot \sum_{i=1}^{n} \tilde{u}_{i}\left[s_{i}(\beta)\right] .
$$




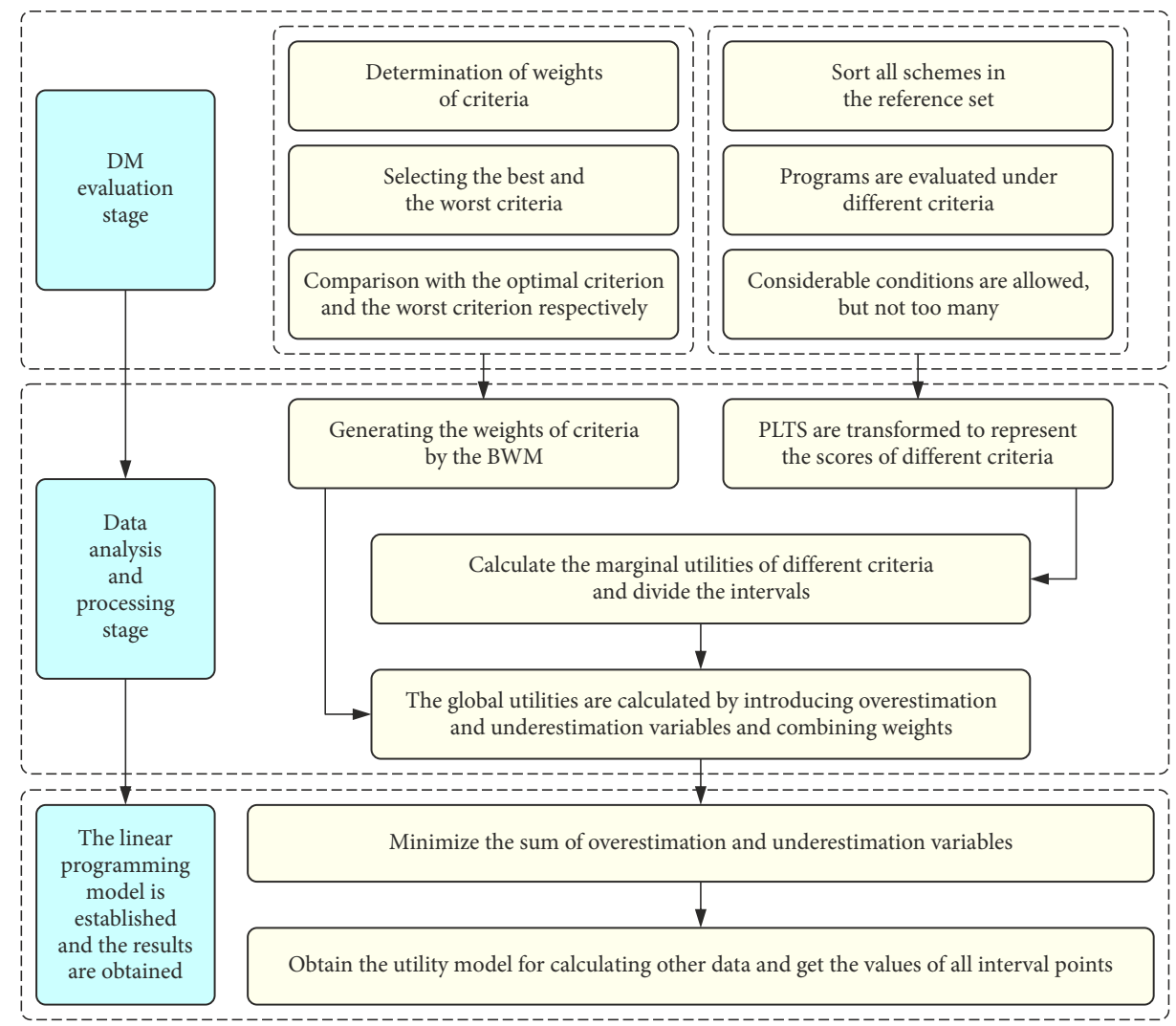

Figure 3. Flowchart of the PL-UTASTAR method

Step 4. The overestimation and underestimation are $\tilde{\varepsilon}^{+}(\beta)$ and $\tilde{\varepsilon}^{-}(\beta)$, respectively. Then, the difference of the utilities of successive opinions can be represented as $\tilde{\Delta}\left(\beta_{x}, \beta_{x+1}\right)$, where:

$$
\begin{aligned}
& \tilde{\Delta}\left(\beta_{x}, \beta_{x+1}\right)=M\left[s\left(\beta_{x}\right)\right]-\tilde{\varepsilon}^{+}\left(\beta_{x}\right)+ \\
& \tilde{\varepsilon}^{-}\left(\beta_{x}\right)-M\left[s\left(\beta_{x+1}\right)\right]+\tilde{\varepsilon}^{+}\left(\beta_{x+1}\right)-\tilde{\varepsilon}^{-}\left(\beta_{x+1}\right) .
\end{aligned}
$$

Step 5. The target of creating a linear programming is to minimize the overestimation and underestimation of all criteria. When a choice is superior to its continuous choice, the global fuzzy utility difference should be greater than the threshold $\gamma$. If two successive schemes are similar, the difference of utilities should be approximately equal to 0 .

$$
\begin{aligned}
& \min \tilde{G}=\sum_{x=1}^{m}\left(\tilde{\varepsilon}^{+}\left(\beta_{x}\right)+\tilde{\varepsilon}^{-}\left(\beta_{x}\right)\right) \\
& \text { s.t.: }\left\{\begin{array}{l}
\Delta\left(\beta_{x}, \beta_{x+1}\right) \geq \tilde{\gamma} \text { if } \beta_{x} \succ \beta_{x+1}, \forall x ; \\
\tilde{\Delta}\left(\beta_{x}, \beta_{x+1}\right) \approx \tilde{0} \text { if } \beta_{x} \sim \beta_{x+1}, \forall x ; \\
\sum_{i=1}^{N} \sum_{j=1}^{b_{i}-1} \lambda_{i j}=1 ; \\
\tilde{\lambda}_{i j} \geq 0, \tilde{\varepsilon}^{+}\left(\beta_{x}\right) \geq 0, \tilde{\varepsilon}^{-}\left(\beta_{x}\right) \geq 0, \forall i, j \text { and } x .
\end{array}\right.
\end{aligned}
$$

We convert PLTSs into crisp numbers (Wu et al. 2018), then the linguistic information does not need to be brought into linear programming calculations, and thus we can use software packages to directly solve linear programming, which is quite convenient.

\subsection{Discussion on the advantages and disadvantages of the PL-UTASTAR method}

The PL-UTASTAR method evaluates and sorts a batch of schemes according to DM's preferences under different criteria. Considering the fuzzy information in DM's evaluations, we express the fuzzy information by PLTSs, which is suitable for people's general expression habit.

The algorithm consists of five steps. There are many different criteria in the evaluation process, so the first step is to determine the weights of different criteria based on the preferences of the DM. Compared with the AHP method, the BWM reduces the calculation work to a certain extent by determining the optimal and the worst criteria and comparing these two criteria with others. The second step is to sort the options in the reference set from the best to the worst and express the evaluations of different options. Considering the fuzzy information in evaluations, PLTSs are used to express the information compatibly. The marginal utilities of options are calculated and the corresponding weights can be multiplied to obtain the global utilities of alternatives in the third step. In the fourth step, we calculate the differences between successive options and introduce two variables: overestimation and underestimation. A linear programming model is established to minimize the combination of all overestimation and underestimation. The model can be calculated through software packages in the fifth step.

There are some advantages of the algorithm:

"»" the weights of criteria are determined by the BWM, which makes the model more accurate than the 
original algorithm. Compared with the traditional AHP, the computational complexity is reduced, especially when the number of criteria is large. In other words, the PL-UTASTAR method can process a larger amount of information more accurately than the original model;

"» PLTSs are used to express and calculate the information in the model, which can express the hesitancy of experts and be pretty suitable for people's expression habits. In the evaluation process, there may be some fuzzy information, which cannot be expressed by exact numbers. The PLTS plays an important role in the model, which can represent not only DM's hesitancy between multiple linguistic items, but also can denote the different degrees of preferences for multiple possible linguistic items. The process of building a model to evaluate more data based on the reference set information requires the DM to evaluate the comprehensiveness of information. The use of PLTSs in the model enables the DM to express information more comprehensively and makes the model more accurate than the original one;

"» although the traditional UTASTAR method and the PL-UTASTAR method calculate the same results in sorting the reference set, there are some differences when it comes to processing more data. The PLUTASTAR method considers the weights of criteria and provides more comprehensive evaluations of objects, making the model more accurate in generating sorting. The results calculated by the original method do not take into account the impression of the weights of criteria, so the evaluations of the schemes with good performances under important criteria are not high.

Of course, there are some shortcomings in the above algorithm, which can be further improved in the future research:

"» the influence of the data quantity of the reference set has an impact on the accuracy of the whole model. Theoretically, the larger the data quantity is, the more accurate the model will be. However, if the data quantity is too large, there will be too much work to build the model. The DM needs to process a certain amount of data to produce an accurate model. The model accuracy and workload need to be trade-off to achieve a balance point;

"» in the third step of the PL-UTASTAR algorithm, PLTSs should be transformed into accurate numbers, which will inevitably result in the loss of original information. If PLTSs are brought into the process of marginal utility calculation, they should retain the original information in theory. The relevant calculation methods need to be further studied and discussed;

"»" in the evaluation process, the preferences of the DM may be expressed by more than one kind of information, so, it is necessary to consider the synthesis of different information representation forms. For example, for the evaluation of the vehicle comfort index, the PLTS is often pretty suitable, while the data of acceleration of vehicle for $100 \mathrm{~km}$ needs to be expressed by a fuzzy number or a precise number. How to bring this information into the calculation of marginal utilities needs further discussion.

\section{Case study}

According to the survey, new energy vehicles have become one of the hottest topics for many enterprises and users in 2019. To demonstrate the effectiveness and accuracy of the PL-UTASTAR method mentioned above, we apply the method to the process of battery supplier selection for new energy vehicles. The order of alternative suppliers in the reference set is calculated by the model, which can process more information of suppliers.

\subsection{Case description}

Renewable resource is a hot topic in contemporary society (Papapostolou et al. 2017; Alizadeh et al. 2020). According to scientific consensus, the emission of greenhouse gases will cause the global warming trend to rise, which will lead to a series of disasters (Nian et al. 2014). Therefore, the widespread use of clean energy and technology upgrading is crucial for development. As a kind of clean energy, electricity is produced by burning fossil fuels, which inevitably produces gas emissions, including a large amount of carbon dioxide (Whittington 2002). With the continuous improvement of technology, the carbon emission brought by electricity will be reduced and the cost will be effectively saved (Sims et al. 2003). Many countries have issued relevant policies to jointly promote environmentally friendly technologies and reduce greenhouse gas emissions (Alizadeh et al. 2015, 2016). As one of the renewable energy batteries, new energy vehicles have been developed for many years. Powered by the improvement of science and technology, the transformation and industrial upgrading is an important way for the development of the automobile industry. Considering green, environmental protection, emission reduction, renewable and other factors, new energy vehicles with lithium batteries have become the future mainstream development direction. In recent years, new energy vehicles have become an increasingly common means of transportation. Compared with traditional gasoline-powered vehicles, new energy vehicles are more environmentally friendly and energy efficient. The government encourages people to buy new energy vehicles and has promulgated many preferential policies, which means that the number of new energy vehicles will continue to rise. With the continuous improvement and maturity of technology, new energy vehicles have become a choice of many manufacturers and users. Liu, Kokko (2013) and Gong et al. (2013) pointed out that new energy vehicles, as one of the promising development directions in the future, are well affected by the policy of the country in the process of development. The state needs to vigorously encourage 
technological development, strive to reduce cost and price, and keep the balance between competitors. By clustering analysis through investigating car-buyers, Carreno et al. (2014) pointed out that the majority of consumers will buy new energy vehicles in the future. Yuan et al. (2015) reviewed the development of new energy vehicles in 2015 and put forward suggestions regarding the future development direction. Yuan and Jiang (2019) provided a model to support the future development of new energy vehicles.

Battery, as one of the core components of new energy vehicles, has a great impact on the overall performance of a vehicle. Diouf and Pode (2015) claimed that lithium battery, which is the main energy storage method of renewable energy, has great potential and advantages. However, the widespread applications of lithium batteries will face many challenges in the future, including the recycling scheme of used batteries (Li et al. 2020). There are many suppliers providing lithium batteries for car companies. New energy automobile companies need to consider various factors of lithium batteries provided by suppliers to decide which supplier's products to use. Therefore, the ranking of alternative lithium battery supplier is very important for the decision-making of new energy automobile company. Reasonable selection of battery suppliers can effectively improve the efficiency of energy suppliers to a certain extent and improve the performance of the whole supply chain (Kaleibari et al. 2016). Jayant et al. (2019) used the MOORA and WASPAS methods to provide a prioritization of supplier development for a battery manufacturing plant in India. Sola and Mota (2012) established a model to select the optimal portfolio selection aiming to replace technologies in industrial motor systems through the MAUT. To our knowledge, no one has applied the UTASTAR family of methods to the field of lithium battery supplier selecting, so it is relatively novel to apply the PL-UTASTAR method to the selection of the supplier of lithium battery in the process of procurement bidding.

New energy automobile company A is one of the largest and most authoritative company in China. Suppose that the company has a new car product and needs to choose a suitable supplier of lithium batteries. There are five lithium battery suppliers $\left\{a_{1}, a_{2}, a_{3}, a_{4}, a_{5}\right\}$ in the reference set who are willing to bid for the project. To select the most suitable supplier for the company, the DM evaluates the suppliers under four criteria $\left\{c_{1}, c_{2}, c_{3}, c_{4}\right\}$ based on a proper LTS. The four evaluation criteria are battery energy density, price, charging speed, and safety. The battery energy density $c_{1}$ means the quality of the battery, including battery capacity, battery size and the suitability with the car; $c_{2}$ is the cost, which represents the supplier's quotation based on material cost and manufacturing cost; the charging speed $c_{3}$ is the rate of the charging speed; $c_{4}$ represents the safety of the battery and the safety factor cannot be ignored in choosing the battery supplier. We need DM to make subjective evaluations on suppliers and the information of the DM is collected for processing. Among all the criteria, the second criterion is a cost criterion and the others are beneficial criteria. The
LTS on the criterion is: $S=\left\{s_{-3}=\right.$ very low,$s_{-2}=$ low, $s_{-1}=$ slightly low, $s_{0}=$ medium, $s_{1}=$ slight high, $s_{2}=$ high, $s_{3}=$ very high $\}$. We make the assumption that all semantics are evenly distributed.

\subsection{Solving the case by the PL-UTASTAR method}

Next, we implement the PL-UTASTAR method in the selection of battery suppliers.

Step 1. Firstly, expert needs to use the BWM to determine the weights of criteria. The invited expert identifies battery energy density $c_{1}$ as the best criteria and charging speed $c_{3}$ as the worst one. The results of the expert comparison of criteria are shown in Tables 1 and 2.

The data in Tables 1 and 2 is used to establish a model as follows to derive the weights of criteria:

$\min \psi$

$$
\text { s.t. : }\left\{\begin{array}{l}
\left|\frac{w_{1}}{w_{2}}-4\right| \leq \psi ; \\
\left|\frac{w_{1}}{w_{3}}-8\right| \leq \psi ; \\
\left|\frac{w_{1}}{w_{4}}-3\right| \leq \psi ; \\
\left|\frac{w_{2}}{w_{3}}-4\right| \leq \psi ; \\
\left|\frac{w_{4}}{w_{3}}-5\right| \leq \psi ; \\
w_{1}+w_{2}+w_{3}+w_{4}=1 \text { and } w_{1}, w_{2}, w_{3}, w_{4} \geq 0 .
\end{array}\right.
$$

Solving this model, we can derive:

$$
\begin{aligned}
& \psi=1.000 ; \\
& w_{1}=0.514 ; \\
& w_{2}=0.171 ; \\
& w_{3}=0.058 ; \\
& w_{4}=0.257
\end{aligned}
$$

Step 2. Suppose that the expert from the automotive purchasing department is invited to evaluate five suppliers $\left\{\beta_{1}, \beta_{2}, \beta_{3}, \beta_{4}, \beta_{5}\right\}$ according to four criteria $\left\{c_{1}, c_{2}, c_{3}, c_{4}\right\}$, where: $c_{1}$ - battery energy density; $c_{2}$ - cost; $c_{3}$ - charging speed; $c_{4}$ - safety. The evaluation is conducted in PLTSs. The data can be tabulated in Table 3 .

Table 1. Compare all criteria with the best criteria

\begin{tabular}{|l|c|c|c|c|}
\hline Criteria: & $c_{1}$ & $c_{2}$ & $c_{3}$ & $c_{4}$ \\
\hline Best criterion: $c_{1}$ & 1 & 4 & 8 & 3 \\
\hline
\end{tabular}

Table 2. Compare all criteria with the worst criteria

\begin{tabular}{|c|c|}
\hline Criteria & Worst criterion $c_{3}$ \\
\hline$c_{1}$ & 8 \\
\hline$c_{2}$ & 4 \\
\hline$c_{3}$ & 1 \\
\hline$c_{4}$ & 5 \\
\hline
\end{tabular}


Table 3. PLTSs of evaluation information

\begin{tabular}{|l|l|l|l|l|l|}
\hline \multirow{2}{*}{ Alternatives } & \multicolumn{4}{|c|}{ Criteria } \\
\cline { 2 - 6 } & battery energy density & \multicolumn{1}{|c|}{ cost } & \multicolumn{1}{|c|}{ charging speed } & \multicolumn{1}{c|}{ safety } \\
\hline Supplier $\beta_{1}$ & $\left\{s_{2}(0.60), s_{3}(0.30)\right\}$ & $\left\{s_{2}(0.50), s_{3}(0.40)\right\}$ & $\left\{s_{2}(0.40), s_{3}(0.60)\right\}$ & $\left\{s_{2}(0.50), s_{3}(0.50)\right\}$ & 1 \\
\hline Supplier $\beta_{2}$ & $\left\{s_{2}(0.80), s_{3}(0.20)\right\}$ & $\left\{s_{1}(0.40), s_{2}(0.30), s_{3}(0.30)\right\}$ & $\left\{s_{1}(0.30), s_{2}(0.70)\right\}$ & $\left\{s_{2}(0.80), s_{3}(0.10)\right\}$ & 2 \\
\hline Supplier $\beta_{3}$ & $\left\{s_{1}(0.40), s_{2}(0.50)\right\}$ & $\left\{s_{0}(0.60), s_{1}(0.30), s_{2}(0.10)\right\}$ & $\left\{s_{2}(0.30), s_{3}(0.70)\right\}$ & $\left\{s_{1}(0.40), s_{2}(0.60)\right\}$ & 3 \\
\hline Supplier $\beta_{4}$ & $\left\{s_{1}(0.50), s_{2}(0.40)\right\}$ & $\left\{s_{-2}(0.30), s_{-1}(0.60)\right\}$ & $\left\{s_{-1}(0.30), s_{0}(0.70)\right\}$ & $\left\{s_{1}(0.30), s_{2}(0.70)\right\}$ & 3 \\
\hline Supplier $\beta_{5}$ & $\left\{s_{0}(0.20), s_{1}(0.70)\right\}$ & $\left\{s_{-3}(0.20), s_{-2}(0.30), s_{-1}(0.50)\right\}$ & $\left\{s_{1}(0.50), s_{2}(0.50)\right\}$ & $\left\{s_{1}(0.60), s_{2}(0.30)\right\}$ & 4 \\
\hline
\end{tabular}

Table 4. Expert's normalized PLTS evaluation information

\begin{tabular}{|l|l|l|l|l|c|}
\hline \multirow{2}{*}{ Alternatives } & \multicolumn{5}{|c|}{ Criteria } \\
\cline { 2 - 6 } & battery energy density & \multicolumn{1}{|c|}{ cost } & \multicolumn{1}{c|}{ charging speed } & \multicolumn{1}{c|}{ safety } & ranking \\
\hline Supplier $\beta_{1}$ & $\left\{s_{2}(0.67), s_{3}(0.33)\right\}$ & $\left\{s_{-3}(0.44), s_{-2}(0.56)\right\}$ & $\left\{s_{2}(0.40), s_{3}(0.60)\right\}$ & $\left\{s_{2}(0.50), s_{3}(0.50)\right\}$ & 1 \\
\hline Supplier $\beta_{2}$ & $\left\{s_{2}(0.80), s_{3}(0.20)\right\}$ & $\left\{s_{1}(0.40), s_{2}(0.30), s_{3}(0.30)\right\}$ & $\left\{s_{1}(0.30), s_{2}(0.70)\right\}$ & $\left\{s_{2}(0.89), s_{3}(0.11)\right\}$ & 2 \\
\hline Supplier $\beta_{3}$ & $\left\{s_{1}(0.44), s_{2}(0.56)\right\}$ & $\left\{s_{0}(0.60), s_{1}(0.30), s_{2}(0.10)\right\}$ & $\left\{s_{2}(0.30), s_{3}(0.70)\right\}$ & $\left\{s_{1}(0.40), s_{2}(0.60)\right\}$ & 3 \\
\hline Supplier $\beta_{4}$ & $\left\{s_{1}(0.56), s_{2}(0.44)\right\}$ & $\left\{s_{1}(0.67), s_{2}(0.33)\right\}$ & $\left\{s_{-1}(0.30), s_{0}(0.70)\right\}$ & $\left\{s_{1}(0.30), s_{2}(0.70)\right\}$ & 3 \\
\hline Supplier $\beta_{5}$ & $\left\{s_{0}(0.22), s_{1}(0.78)\right\}$ & $\left\{s_{-3}(0.20), s_{-2}(0.30), s_{-1}(0.50)\right\}$ & $\left\{s_{1}(0.50), s_{2}(0.50)\right\}$ & $\left\{s_{1}(0.67), s_{2}(0.33)\right\}$ & 4 \\
\hline
\end{tabular}

Among these criteria, $c_{2}$ is a cost criterion and the others are benefit criteria. Therefore, we should first transform the cost criterion into the benefit criterion by swapping the subscript of the PLTS. For example, the expression of the cost criterion $\left\{s_{0}(0.60), s_{1}(0.30), s_{2}(0.10)\right\}$ can be converted to the presentation of the benefit criterion $\left\{s_{-2}(0.10), s_{-1}(0.30), s_{0}(0.60)\right\}$. The normalized PLTSs can be obtained in Table 4 .

Step 3. Calculate the scores of all PLTSs in Table 4 by Equation (8), which will facilitate our subsequent calculation. The results can be clearly seen in Table 5 .

Besides, we need to compute the evaluation scale sections of each criterion. In this supplier selection problem, we arrange the second criterion with three evaluation scale sections and others with three evaluation scale sections (Table 6). For instance, the second criterion is distributed between 0.093 and 0.784 . The minimum boundary is the minimum value in the expert evaluation and the maximum boundary is the maximum value in the expert evaluation. $\gamma$ and $\varphi$ represent the threshold values and we suppose that $\gamma=0.05$ and $\varphi=0.01$.

The utilities of the alternatives can be calculated by:

$$
\begin{aligned}
& M\left(\beta_{1}\right)=w_{1} \cdot u_{1}\left[s_{1}\left(\beta_{1}\right)\right]+w_{2} \cdot u_{2}\left[s_{2}\left(\beta_{1}\right)\right]+ \\
& w_{3} \cdot u_{3}\left[s_{3}\left(\beta_{1}\right)\right]+w_{4} \cdot u_{4}\left[s_{3}\left(\beta_{1}\right)\right] .
\end{aligned}
$$

For criterion 1 , the interval end points are $s_{1^{*}}=s_{1}^{0}=$ $0.63, s_{1}^{1}=0.7595, s_{1}^{2}=0.889$. We can infer that $s_{1}\left(a_{1}\right)$ is in
Table 5. The scores of NPLTS

\begin{tabular}{|l|c|c|c|c|c|}
\hline \multirow{2}{*}{ Alternatives } & \multicolumn{5}{|c|}{ Criteria } \\
\cline { 2 - 6 } & $\begin{array}{c}\text { battery } \\
\text { energy } \\
\text { density }\end{array}$ & cost & $\begin{array}{c}\text { charging } \\
\text { speed }\end{array}$ & safety & Ranking \\
\hline Supplier $\beta_{1}$ & 0.889 & 0.093 & 0.933 & 0.917 & 1 \\
\hline Supplier $\beta_{2}$ & 0.867 & 0.183 & 0.783 & 0.852 & 2 \\
\hline Supplier $\beta_{3}$ & 0.759 & 0.417 & 0.950 & 0.767 & 3 \\
\hline Supplier $\beta_{4}$ & 0.741 & 0.722 & 0.450 & 0.783 & 3 \\
\hline Supplier $\beta_{5}$ & 0.630 & 0.784 & 0.750 & 0.722 & 4 \\
\hline
\end{tabular}

the second section of the first criterion. By Equation (12), we can calculate the marginal utility function:

$$
u_{1}\left[s_{1}\left(\beta_{1}\right)\right]=\lambda_{11}+\frac{s_{1}(\beta)-s_{1}^{1}}{\left(s_{1}^{2}-s_{1}^{1}\right)} \cdot \lambda_{12}=\lambda_{11}+\lambda_{12} .
$$

Similarly, we can count the utilities of other criteria. The scores of $s_{2}\left(a_{1}\right), s_{3}\left(a_{1}\right)$ and $s_{4}\left(a_{1}\right)$ are distributed in the first and second sections, respectively, under the criteria "cost", "charging speed" and "safety".

$$
\begin{aligned}
& u_{2}\left[s_{1}\left(\beta_{1}\right)\right]=0 \cdot \lambda_{21}+0 \cdot \lambda_{22}+0 \cdot \lambda_{23} ; \\
& u_{3}\left[s_{1}\left(\beta_{1}\right)\right]=\lambda_{31}+0.932 \cdot \lambda_{32} ; \\
& u_{4}\left[s_{1}\left(\beta_{1}\right)\right]=\lambda_{41}+\lambda_{42} .
\end{aligned}
$$


Table 6. Segmentation of criteria value ranges into intervals

\begin{tabular}{|c|c|c|c|c|c|c|c|c|}
\hline Criterion & Min & Max & Spread & Sections & Step & Section 1 & Section 2 & Section 3 \\
\hline$c_{1}$ & 0.630 & 0.889 & 0.259 & 2 & 0.1295 & {$[0.630,0.7595]$} & {$[0.7595,0.889]$} & - \\
\hline$c_{2}$ & 0.093 & 0.784 & 0.691 & 3 & 0.230 & {$[0.093,0.323]$} & {$[0.323,0.553]$} & {$[0.553,0.784]$} \\
\hline$c_{3}$ & 0.450 & 0.950 & 0.500 & 2 & 0.250 & {$[0.450,0.700]$} & {$[0.700,0.950]$} & - \\
\hline$c_{4}$ & 0.722 & 0.917 & 0.195 & 2 & 0.0975 & {$[0.722,0.820]$} & {$[0.820,0.917]$} & - \\
\hline
\end{tabular}

The global utility of scheme $\beta_{1}$ is:

$$
\begin{aligned}
& M\left(\beta_{1}\right)=w_{1} \cdot u_{1}\left[s_{1}\left(\beta_{1}\right)\right]+w_{2} \cdot u_{2}\left[s_{2}\left(\beta_{1}\right)\right]+ \\
& w_{3} \cdot u_{3}\left[s_{3}\left(\beta_{1}\right)\right]+w_{4} \cdot u_{4}\left[s_{4}\left(\beta_{1}\right)\right]= \\
& 0.514 \cdot \lambda_{11}+0.514 \cdot \lambda_{12}+0.058 \cdot \lambda_{31}+ \\
& 0.054 \cdot \lambda_{32}+0.257 \cdot \lambda_{41}+0.257 \cdot \lambda_{42} .
\end{aligned}
$$

Similarly, we can calculate the global utility value of other schemes by:

$$
\begin{aligned}
& M\left(\beta_{2}\right)=0.514 \cdot \lambda_{11}+0.427 \cdot \lambda_{12}+0.0669 \cdot \lambda_{21}+ \\
& 0.058 \cdot \lambda_{31}+0.0193 \cdot \lambda_{32}+0.257 \cdot \lambda_{41}+0.0848 \cdot \lambda_{42} ; \\
& M\left(\beta_{3}\right)=0.5119 \cdot \lambda_{11}+0.171 \cdot \lambda_{21}+0.0699 \cdot \lambda_{22}+ \\
& 0.058 \cdot \lambda_{31}+0.058 \cdot \lambda_{32}+0.1180 \cdot \lambda_{41} ; \\
& M\left(\beta_{4}\right)=0.4406 \cdot \lambda_{11}+0.171 \cdot \lambda_{21}+ \\
& 0.171 \cdot \lambda_{22}+0.1252 \cdot \lambda_{23}+0.1599 \cdot \lambda_{41} ; \\
& M\left(\beta_{5}\right)=0.171 \cdot \lambda_{21}+0.171 \cdot \lambda_{22}+ \\
& 0.171 \cdot \lambda_{23}+0.058 \cdot \lambda_{31}+0.0116 \cdot \lambda_{32} .
\end{aligned}
$$

Step 4. We calculate the overestimate and underestimate functions $\varepsilon^{+}\left(\beta_{x}\right)$ and $\varepsilon^{-}\left(\beta_{x}\right)$ for each scheme by:

$$
\begin{aligned}
& M\left(\beta_{1}\right)=0.514 \cdot \lambda_{11}+0.514 \cdot \lambda_{12}+0.058 \cdot \lambda_{31}+ \\
& 0.054 \cdot \lambda_{32}+0.257 \cdot \lambda_{41}+0.257 \cdot \lambda_{42}+ \\
& \varepsilon^{-}\left(\beta_{1}\right)-\varepsilon^{+}\left(\beta_{1}\right) ; \\
& M\left(\beta_{2}\right)=0.514 \cdot \lambda_{11}+0.427 \cdot \lambda_{12}+0.0669 \lambda_{21}+ \\
& 0.058 \cdot \lambda_{31}+0.0193 \lambda_{32}+0.257 \cdot \lambda_{41}+ \\
& 0.0848 \cdot \lambda_{42}+\varepsilon^{-}\left(\beta_{2}\right)-\varepsilon^{+}\left(\beta_{2}\right) ; \\
& M\left(\beta_{3}\right)=0.5119 \cdot \lambda_{11}+0.171 \cdot \lambda_{21}+0.0699 \cdot \lambda_{22}+ \\
& 0.058 \cdot \lambda_{31}+0.058 \cdot \lambda_{32}+0.1180 \cdot \lambda_{41}+ \\
& \varepsilon^{-}\left(\beta_{3}\right)-\varepsilon^{+}\left(\beta_{3}\right) ; \\
& M\left(\beta_{4}\right)=0.4406 \cdot \lambda_{11}+0.171 \cdot \lambda_{21}+0.171 \cdot \lambda_{22}+ \\
& 0.1252 \cdot \lambda_{23}+0.1599 \cdot \lambda_{41}+\varepsilon^{-}\left(\beta_{4}\right)-\varepsilon^{+}\left(\beta_{4}\right) ; \\
& M\left(\beta_{5}\right)=0.171 \cdot \lambda_{21}+0.171 \cdot \lambda_{22}+0.171 \cdot \lambda_{23}+ \\
& 0.058 \cdot \lambda_{31}+0.0116 \cdot \lambda_{32}+\varepsilon^{-}\left(\beta_{5}\right)-\varepsilon^{+}\left(\beta_{5}\right) .
\end{aligned}
$$

Next, we calculate the utility difference values between continuous schemes by:

$\Delta M_{\beta_{1} \beta_{2}}=\left\{0.514 \cdot \lambda_{11}+0.514 \cdot \lambda_{12}+0.058 \cdot \lambda_{31}+0.054 \cdot \lambda_{32}+\right.$ $\left.0.257 \cdot \lambda_{41}+0.257 \cdot \lambda_{42}+\varepsilon^{-}\left(\beta_{1}\right)-\varepsilon^{+}\left(\beta_{1}\right)\right\}-$ $\left\{0.514 \cdot \lambda_{11}+0.427 \cdot \lambda_{12}+0.0669 \cdot \lambda_{21}+0.058 \cdot \lambda_{31}+0.0193 \cdot \lambda_{32}+\right.$ $\left.0.257 \cdot \lambda_{41}+0.0848 \cdot \lambda_{42}+\varepsilon^{-}\left(\beta_{2}\right)-\varepsilon^{+}\left(\beta_{2}\right)\right\}=$ $0.087 \cdot \lambda_{12}-0.0669 \cdot \lambda_{21}+0.0347 \cdot \lambda_{32}+0.1722 \cdot \lambda_{42}+$ $\varepsilon^{-}\left(\beta_{1}\right)-\varepsilon^{+}\left(\beta_{1}\right)-\varepsilon^{-}\left(\beta_{2}\right)+\varepsilon^{+}\left(\beta_{2}\right) ;$ $\Delta M_{\beta_{2} \beta_{3}}=\left\{0.514 \cdot \lambda_{11}+0.427 \cdot \lambda_{12}+0.0669 \cdot \lambda_{21}+0.058 \cdot \lambda_{31}+\right.$ $\left.0.0193 \cdot \lambda_{32}+0.257 \cdot \lambda_{41}+0.0848 \cdot \lambda_{42}+\varepsilon^{-}\left(\beta_{2}\right)-\varepsilon^{+}\left(\beta_{2}\right)\right\}-$ $\left\{0.5119 \cdot \lambda_{11}+0.171 \cdot \lambda_{21}+0.0699 \cdot \lambda_{22}+0.058 \cdot \lambda_{31}+\right.$ $\left.0.058 \cdot \lambda_{32}+0.1180 \cdot \lambda_{41}+\varepsilon^{-}\left(\beta_{3}\right)-\varepsilon^{+}\left(\beta_{3}\right)\right\}=$ $0.0021 \cdot \lambda_{11}+0.427 \cdot \lambda_{12}-0.1041 \cdot \lambda_{21}-0.0699 \cdot \lambda_{22}-$ $0.0387 \cdot \lambda_{32}+0.139 \cdot \lambda_{41}+0.0848 \cdot \lambda_{42}+\varepsilon^{-}\left(\beta_{2}\right)-$ $\varepsilon^{+}\left(\beta_{2}\right)-\varepsilon^{-}\left(\beta_{3}\right)+\varepsilon^{+}\left(\beta_{3}\right) ;$ $\Delta M_{\beta_{3} \beta_{4}}=\left\{0.5119 \cdot \lambda_{11}+0.171 \cdot \lambda_{21}+0.0699 \cdot \lambda_{22}+0.058 \cdot \lambda_{31}+\right.$ $\left.0.058 \cdot \lambda_{32}+0.1180 \cdot \lambda_{41}+\varepsilon^{-}\left(\beta_{3}\right)-\varepsilon^{+}\left(\beta_{3}\right)\right\}-$ $\left\{0.4406 \cdot \lambda_{11}+0.171 \cdot \lambda_{21}+0.171 \cdot \lambda_{22}+0.1252 \cdot \lambda_{23}+\right.$ $\left.0.1599 \cdot \lambda_{41}+\varepsilon^{-}\left(\beta_{4}\right)-\varepsilon^{+}\left(\beta_{4}\right)\right\}=0.0713 \cdot \lambda_{11}-0.1011 \cdot \lambda_{22}-$ $0.1252 \cdot \lambda_{23}+0.058 \cdot \lambda_{31}+0.058 \cdot \lambda_{32}-0.0419 \cdot \lambda_{41}+$ $\varepsilon^{-}\left(\beta_{3}\right)-\varepsilon^{+}\left(\beta_{3}\right)-\varepsilon^{-}\left(\beta_{4}\right)+\varepsilon^{+}\left(\beta_{4}\right) ;$ $\Delta M_{\beta_{4} \beta_{5}}=\left\{0.4406 \cdot \lambda_{11}+0.171 \cdot \lambda_{21}+0.171 \cdot \lambda_{22}+0.1252 \cdot \lambda_{23}+\right.$ $\left.0.1599 \cdot \lambda_{41}+\varepsilon^{-}\left(\beta_{4}\right)-\varepsilon^{+}\left(\beta_{4}\right)\right\}-$ $\left\{0.171 \cdot \lambda_{21}+0.171 \cdot \lambda_{22}+0.171 \cdot \lambda_{23}+0.058 \cdot \lambda_{31}+\right.$ $\left.0.0116 \cdot \lambda_{32}+\varepsilon^{-}\left(\beta_{5}\right)-\varepsilon^{+}\left(\beta_{5}\right)\right\}=$ $0.4406 \cdot \lambda_{11}-0.0458 \cdot \lambda_{23}-0.058 \cdot \lambda_{31}-0.0116 \cdot \lambda_{32}+$ $0.1599 \cdot \lambda_{41}+\varepsilon^{-}\left(\beta_{4}\right)-\varepsilon^{+}\left(\beta_{4}\right)-\varepsilon^{-}\left(\beta_{5}\right)+\varepsilon^{+}\left(\beta_{5}\right)$.

The order provided by the DM from the reference set is $\beta_{1} \succ \beta_{2} \succ \beta_{3} \sim \beta_{4} \succ \beta_{5}$. Among them $\beta_{1}$ is preferred than $\beta_{2}$, and $\beta_{3}$ is the same level as $\beta_{4}$ and so on. To ensure the distinctiveness of the difference, we set the threshold $\gamma$ is 0.05 in our example. Then, the inequality relations are expressed as follows:

$$
\begin{aligned}
& \Delta M_{\beta_{1} \beta_{2}} \geq \gamma ; \\
& \Delta M_{\beta_{2} \beta_{3}} \geq \gamma ; \\
& \Delta M_{\beta_{3} \beta_{4}}=0 ; \\
& \Delta M_{\beta_{4} \beta_{5}} \geq \gamma .
\end{aligned}
$$

Step 5. To establish a linear programming model, the objective function is $\sum_{x=1}^{5}\left(\varepsilon^{+}\left(\beta_{x}\right)+\varepsilon^{-}\left(\beta_{x}\right)\right)$ and the con- 
straints are $\Delta M_{\beta_{1} \beta_{2}} \geq \gamma, \Delta M_{\beta_{3} \beta_{4}}=0$, and so forth. Besides, one significant constraint is $\sum_{i=1}^{4} \sum_{j=1}^{3} \lambda_{i j}=1$, which defines the boundary of the sum of utility functions. Then, a linear programming is established as:

$$
\begin{aligned}
& \min \tilde{G}=\sum_{x=1}^{5}\left(\tilde{\varepsilon}^{+}\left(\beta_{x}\right)+\tilde{\varepsilon}^{-}\left(\beta_{x}\right)\right) \\
& \text { s.t.: }\left\{\begin{array}{l}
\Delta\left(\beta_{x}, \beta_{x+1}\right) \geq \tilde{\gamma} \text { if } \beta_{x} \succ \beta_{x+1}, \forall x ; \\
\tilde{\Delta}\left(\beta_{x}, \beta_{x+1}\right) \approx \tilde{0} \text { if } \beta_{x} \sim \beta_{x+1}, \forall x ; \\
\sum_{i=1}^{4} \sum_{j=1}^{3} \lambda_{i j}=1 ; \\
\tilde{\lambda}_{i j} \geq 0, \tilde{\varepsilon}^{+}\left(\beta_{x}\right) \geq 0, \tilde{\varepsilon}^{-}\left(\beta_{x}\right) \geq 0, \forall i, j \text { and } x .
\end{array}\right.
\end{aligned}
$$

The linear programming can be seen clearly in Table 7 .

Table 7 is presented as a vertical table and the last column is the objective function. The results of the linear programming calculated by the software are:

$$
\begin{aligned}
& \lambda_{11}=0.1471 ; \\
& \lambda_{12}=0.1139 ; \\
& \lambda_{21}=0.00 ; \\
& \lambda_{22}=0.00 ;
\end{aligned}
$$

Table 7. The expression of the linear programming problem

\begin{tabular}{|l|c|c|c|c|c|c|}
\hline \multicolumn{1}{|c|}{ Variable } & \multicolumn{5}{|c|}{ Coefficient } \\
\hline$\lambda_{11}$ & & 0.002 & 0.071 & 0.441 & 1 & \\
\hline$\lambda_{12}$ & 0.087 & 0.427 & & & 1 & \\
\hline$\lambda_{21}$ & -0.067 & -0.104 & & & 1 & \\
\hline$\lambda_{22}$ & & -0.070 & -0.101 & & 1 & \\
\hline$\lambda_{23}$ & & & -0.125 & -0.046 & 1 & \\
\hline$\lambda_{31}$ & & & 0.058 & -0.058 & 1 & \\
\hline$\lambda_{32}$ & 0.035 & -0.039 & 0.058 & -0.012 & 1 & \\
\hline$\lambda_{41}$ & & 0.139 & -0.042 & 0.160 & 1 & \\
\hline$\lambda_{42}$ & 0.172 & 0.085 & & & 1 & \\
\hline$\varepsilon^{+}\left(\beta_{1}\right)$ & -1 & & & & & 1 \\
\hline$\varepsilon^{-}\left(\beta_{1}\right)$ & 1 & & & & & 1 \\
\hline$\varepsilon^{+}\left(\beta_{2}\right)$ & 1 & -1 & & & & 1 \\
\hline$\varepsilon^{-}\left(\beta_{2}\right)$ & -1 & 1 & & & & 1 \\
\hline$\varepsilon^{+}\left(\beta_{3}\right)$ & & 1 & -1 & & & 1 \\
\hline$\varepsilon^{-}\left(\beta_{3}\right)$ & & -1 & 1 & & & 1 \\
\hline$\varepsilon^{+}\left(\beta_{4}\right)$ & & & 1 & -1 & & 1 \\
\hline$\varepsilon^{-}\left(\beta_{4}\right)$ & & & -1 & 1 & & 1 \\
\hline$\varepsilon^{+}\left(\beta_{5}\right)$ & & & & 1 & & 1 \\
\hline$\varepsilon^{-}\left(\beta_{5}\right)$ & & & & -1 & & 1 \\
\hline$\tilde{\gamma}$ & & & & & & \\
\hline
\end{tabular}

$$
\begin{aligned}
& \lambda_{23}=0.2389 ; \\
& \lambda_{31}=0.00 ; \\
& \lambda_{32}=0.3348 ; \\
& \lambda_{41}=0.00 ; \\
& \lambda_{42}=0.1654 ; \\
& \tilde{G}=\varepsilon^{-}\left(\beta_{1}\right)=\varepsilon^{+}\left(\beta_{1}\right)=\varepsilon^{-}\left(\beta_{2}\right)=\varepsilon^{+}\left(\beta_{2}\right)= \\
& \varepsilon^{-}\left(\beta_{3}\right)=\varepsilon^{+}\left(\beta_{3}\right)=\varepsilon^{-}\left(\beta_{4}\right)=\varepsilon^{+}\left(\beta_{4}\right)= \\
& \varepsilon^{-}\left(\beta_{5}\right)=\varepsilon^{+}\left(\beta_{5}\right)=0 .
\end{aligned}
$$

Based on the above results, the utility values can be calculated by:

$$
M=M_{\text {density }}+M_{\text {cost }}+M_{\text {speed }}+M_{\text {safety }} .
$$

Then, the utility of different part can be represented as follows:

$$
\tilde{M}_{\text {density }}(\tilde{\beta})=\left\{\begin{array}{l}
\text { par }_{1} \text {,if } \tilde{\beta}_{\text {density }} \in[0.63,0.7595) \\
\text { par } 2, \text { if } \tilde{\beta}_{\text {density }} \in[0.7595,0.889]
\end{array}\right.
$$

where:

$$
\begin{aligned}
& \operatorname{par}_{1}=\frac{\tilde{\beta}_{\text {density }}-0.63}{0.1295} \cdot \tilde{\lambda}_{11} ; \\
& \operatorname{par}_{2}=\tilde{\lambda}_{11}+\frac{\tilde{\beta}_{\text {density }}-0.7595}{0.1295} \cdot \tilde{\lambda}_{21} ; \\
& \tilde{M}_{\text {cost }}(\tilde{\beta})=\left\{\begin{array}{l}
\text { par }, \text { if } \tilde{\beta}_{\text {cost }} \in[0.093,0.323) ; \\
\text { par }_{2}, \text { if } \tilde{\beta}_{\text {cost }} \in[0.323,0.553) ; \\
\text { par }_{3}, \text { if } \tilde{\beta}_{\text {cost }} \in[0.553,0.784],
\end{array}\right.
\end{aligned}
$$

where:

$$
\begin{aligned}
& \text { par }_{1}=\frac{\tilde{\beta}_{\text {cost }}-0.093}{0.230} \cdot \tilde{\lambda}_{21} ; \\
& \text { par }_{2}=\tilde{\lambda}_{21}+\frac{\tilde{\beta}_{\text {cost }}-0.323}{0.230} \cdot \tilde{\lambda}_{22} ; \\
& \text { par }_{3}=\tilde{\lambda}_{21}+\tilde{\lambda}_{22}+\frac{\tilde{\beta}_{\text {cost }}-0.553}{0.230} \cdot \tilde{\lambda}_{23} ; \\
& \tilde{M}_{\text {speed }}(\tilde{\beta})=\left\{\begin{array}{l}
\text { par } \\
\text { par }, \text { if } \tilde{\beta}_{\text {speed }} \in[0.450,0.700) ; \\
\text { paf } \tilde{\beta}_{\text {speed }} \in[0.700,0.950],
\end{array}\right.
\end{aligned}
$$

where:

$$
\begin{aligned}
& \text { par }_{1}=\frac{\tilde{\beta}_{\text {speed }}-0.450}{0.250} \cdot \tilde{\lambda}_{31} ; \\
& \text { par }_{2}=\tilde{\lambda}_{31}+\frac{\tilde{\beta}_{\text {speed }}-0.700}{0.250} \cdot \tilde{\lambda}_{32} ; \\
& \tilde{M}_{\text {safety }}(\tilde{\beta})=\left\{\begin{array}{l}
\text { par, if } \tilde{\beta}_{\text {safety }} \in[0.722,0.820) ; \\
\text { par } 2, \text { if } \tilde{\beta}_{\text {safety }} \in[0.820,0.917],
\end{array}\right.
\end{aligned}
$$

where:

$$
\begin{aligned}
& \operatorname{par}_{1}=\frac{\tilde{\beta}_{\text {safety }}-0.722}{0.0975} \cdot \tilde{\lambda}_{41} ; \\
& \operatorname{par}_{2}=\tilde{\lambda}_{41}+\frac{\tilde{\beta}_{\text {safety }}-0.820}{0.0975} \cdot \tilde{\lambda}_{42} .
\end{aligned}
$$


Using these expressions, we can get the utility values of the reference set and other schemes. All we need to do is to distinguish the interval of utility function. Using the above formula, the utilities of the five schemes in our case are calculated as:

$$
\begin{aligned}
& M\left(\beta_{1}\right)=0.1947 ; \\
& M\left(\beta_{2}\right)=0.1447 ; \\
& M\left(\beta_{3}\right)=0.0947 ; \\
& M\left(\beta_{4}\right)=0.0947 ; \\
& M\left(\beta_{5}\right)=0.0447
\end{aligned}
$$

The results are consistent with the first order $\beta_{1} \succ \beta_{2} \succ$ $\beta_{3} \sim \beta_{4} \succ \beta_{5}$ given by the expert. Using the utility function model, we can process and sort a large number of scheme data.

Compared with the traditional UTASTAR and fuzzy UTASTAR methods, our method considers the weights of criteria and is suitable with the habits of people from the perspective of linguistic expressing.

\subsection{The calculation results of the original UTASTAR method}

For comparing, we suppose the DM evaluated the criteria and schemes for the same reference set by the original UTASTAR method. The evaluation information can be expressed and shown in Table 8.

By the original UTASTAR method, we can get the following results:

$$
\begin{aligned}
& \lambda_{11}=0.472 ; \\
& \lambda_{12}=0 ; \\
& \lambda_{21}=0 ; \\
& \lambda_{22}=0.094 ; \\
& \lambda_{23}=0.331 ; \\
& \lambda_{31}=0 ; \\
& \lambda_{32}=0 ; \\
& \lambda_{41}=0.053 ; \\
& \lambda_{42}=0.05 ; \\
& \tilde{G}=\varepsilon^{-}\left(\beta_{1}\right)=\varepsilon^{+}\left(\beta_{1}\right)=\varepsilon^{-}\left(\beta_{2}\right)=\varepsilon^{+}\left(\beta_{2}\right)= \\
& \varepsilon^{-}\left(\beta_{3}\right)=\varepsilon^{+}\left(\beta_{3}\right)=\varepsilon^{-}\left(\beta_{4}\right)=\varepsilon^{+}\left(\beta_{4}\right)= \\
& \varepsilon^{-}\left(\beta_{5}\right)=\varepsilon^{+}\left(\beta_{5}\right)=0 .
\end{aligned}
$$

Table 8. Expert's evaluation information for the original UTASTAR method

\begin{tabular}{|l|c|c|c|c|c|}
\hline \multirow{2}{*}{ Alternatives } & \multicolumn{5}{|c|}{ Criteria } \\
\cline { 2 - 6 } & $\begin{array}{c}\text { battery } \\
\text { energy } \\
\text { density }\end{array}$ & cost & $\begin{array}{c}\text { charging } \\
\text { speed }\end{array}$ & safety & ranking \\
\hline Supplier $\beta_{1}$ & 9 & 3 & 9 & 9 & 1 \\
\hline Supplier $\beta_{2}$ & 8 & 5 & 7.5 & 8 & 2 \\
\hline Supplier $\beta_{3}$ & 7.5 & 6.5 & 9.5 & 7.5 & 3 \\
\hline Supplier $\beta_{4}$ & 7 & 8 & 4.5 & 7.5 & 3 \\
\hline Supplier $\beta_{5}$ & 6.5 & 9 & 6.5 & 7 & 4 \\
\hline
\end{tabular}

Then, the utility functions can be established according to these results as:

$$
\tilde{M}_{\text {density }}(\tilde{\beta})=\left\{\begin{array}{l}
\text { par }, \text { if } \tilde{\beta}_{\text {density }} \in[6.5,7.75) ; \\
\text { par } 2 \text {, if } \tilde{\beta}_{\text {density }} \in[7.75,9],
\end{array}\right.
$$

where:

$$
\begin{aligned}
& \text { par }_{1}=\frac{\tilde{\beta}_{\text {density }}-6.5}{1.25} \cdot \tilde{\lambda}_{11} ; \\
& \text { par }_{2}=\tilde{\lambda}_{11}+\frac{\tilde{\beta}_{\text {density }}-7.75}{1.25} \cdot \tilde{\lambda}_{12} ; \\
& \tilde{M}_{\text {cost }}(\tilde{\beta})=\left\{\begin{array}{l}
\operatorname{par}_{1}, \text { if } \tilde{\beta}_{\text {cost }} \in[3,5) ; \\
\text { par }_{2}, \text { if } \tilde{\beta}_{\text {cost }} \in[5,7) ; \\
\text { par }_{3}, \text { if } \tilde{\beta}_{\text {cost }} \in[7,9],
\end{array}\right.
\end{aligned}
$$

where:

$$
\begin{aligned}
& \text { par }_{1}=\frac{\tilde{\beta}_{\text {cost }}-3}{2} \cdot \tilde{\lambda}_{21} ; \\
& \text { par }_{2}=\tilde{\lambda}_{21}+\frac{\tilde{\beta}_{\text {cost }}-5}{2} \cdot \tilde{\lambda}_{22} ; \\
& \text { par }_{3}=\tilde{\lambda}_{21}+\tilde{\lambda}_{22}+\frac{\tilde{\beta}_{\text {cost }}-7}{2} \cdot \tilde{\lambda}_{23} ; \\
& \tilde{M}_{\text {speed }}(\tilde{\beta})=\left\{\begin{array}{l}
\text { par }, \text { if } \tilde{\beta}_{\text {speed }} \in[4.5,7) ; \\
\text { par }_{2}, \text { if } \tilde{\beta}_{\text {speed }} \in[7,9.5],
\end{array}\right.
\end{aligned}
$$

where:

$$
\begin{aligned}
& \operatorname{par}_{1}=\frac{\tilde{\beta}_{\text {speed }}-4.5}{2.5} \cdot \tilde{\lambda}_{31} ; \\
& \operatorname{par}_{2}=\tilde{\lambda}_{31}+\frac{\tilde{\beta}_{\text {speed }}-7}{2.5} \cdot \tilde{\lambda}_{32} ; \\
& \tilde{M}_{\text {safety }}(\tilde{\beta})=\left\{\begin{array}{l}
\text { par }_{1}, \text { if } \tilde{\beta}_{\text {safety }} \in[7,8) ; \\
\text { par }_{2}, \text { if } \tilde{\beta}_{\text {safety }} \in[8,9],
\end{array}\right.
\end{aligned}
$$

where:

$$
\begin{aligned}
& \operatorname{par}_{1}=\frac{\tilde{\beta}_{\text {safety }}-7}{1} \cdot \tilde{\lambda}_{41} ; \\
& \operatorname{par}_{2}=\tilde{\lambda}_{41}+\frac{\tilde{\beta}_{\text {safety }}-8}{1} \cdot \tilde{\lambda}_{42} .
\end{aligned}
$$

Using the above utility functions, the utilities of the five schemes in our case are calculated as:

$$
\begin{aligned}
& M\left(\beta_{1}\right)=0.575 ; \\
& M\left(\beta_{2}\right)=0.525 ; \\
& M\left(\beta_{3}\right)=0.4746 ; \\
& M\left(\beta_{4}\right)=0.4748 ; \\
& M\left(\beta_{5}\right)=0.425
\end{aligned}
$$

The schemes are ranked as $\beta_{1} \succ \beta_{2} \succ \beta_{3} \sim \beta_{4} \succ \beta_{5}$.

The results of the original UTASTAR method and the PL-UTASTAR method are plotted in Figure 4. From this figure, it can be seen that the difference between the maximum and minimum utility values of the reference set calculated by the original UTASTAR method is not large. 


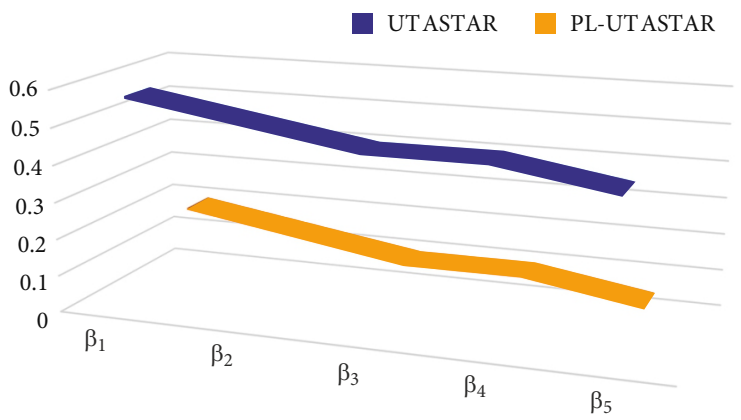

Figure 4. The results of the two methods

However, the differences between the maximum and the minimum utility values calculated by PL-UTASTAR method are large. This means that the model calculated by the PL-UTASTAR method can accurately partition the data, which makes the calculation results consistent with the personal preference of the DM. The main reason for this result is that there is a large difference in the weights of criteria in the minds of the DM.

From the above case study, we can find that the PLUTASTAR method proposed in this study has certain management significance:

"»" firstly, the model can deal with the hesitant information of experts in the evaluation process, and can transform the information inconsistent with people's linguistic expression habits, which will reduce the risk of information loss in information collection; besides, it is persuasive to sort the schemes through the model, especially when there is a large amount of data, given that this method provides a precise model for the DM to sort the schemes;

"» secondly, in the selection process of battery suppliers, all evaluation standards cannot be regarded as the same importance; the standards that have a great impact on the performance of the model should be focused on to facilitate the purchasing personnel to select the appropriate supplier;

"» thirdly, the PL-UTASTAR method takes the personal evaluation preference information of the expert into account in the model. It can be seen that the weight of battery energy density is the largest; therefore, in the future evaluation process, we should pay more attention to the energy density of battery and make an accurate evaluation of battery energy density, which will make the results of model calculation accurate.

\section{Discussions}

In this section, we discuss some features and advantages of the algorithm. The main characteristics of this method could be summarized as follows:

"» different from the traditional UTASTAR and fuzzy UTASTAR methods, our proposed PL-UTASTAR model can not only process fuzzy evaluation information, but also conform to the evaluation habits of experts. Since the evaluation model can be used to process more data, a more realistic model is needed to process the evaluation information of experts. Using PLTSs in the method makes the model consistent with the evaluation habits of experts;

"'» in the process of evaluation, the weights of criteria often have a great influence on the final ranking result, so it is necessary to determine the weights of criteria firstly. When the weight differences of criterion are large, using the original UTASTAR method, we will get the utility values, which are very different from our expectation. As a widely used weight determination method, the BWM is well suitable to our model, which can reduce the amount of pairwise comparisons in determining the weights of criteria;

"'» this model can calculate the ranking of projects according to expert's evaluations and it can be used to process more data. Facing with a large number of alternatives, the schemes can be sorted according to experts' preferences efficiently and conveniently.

Apart from the above advantages, there are still some limitations that need to be overcome through further research:

"») when using PLTSs to calculate scores, the original information may be lost to some extent. If PLTSs can be brought into the calculation process of the model, the result will contain more original information. How to realize this process needs to be explored in the future research;

"'» in the process of multi-attribute decision-making, the weights and evaluation information could be changed over time. Taking the factor of time into consideration, the model will be able to deal with different alternatives in the future;

"»" in the evaluation process, experts may put forward different expressions for alternatives under different criteria, which makes the evaluations conform to the personal preferences of experts. Different forms of information processing need to be studied in the future.

\section{Conclusions}

The development of new energy vehicles is one of the key points to solve the environmental pollution problem. As a core component of new energy vehicles, the battery could affect the performance parameters of all aspects of vehicles. To choose the battery of new energy vehicles more reasonably, many enterprises need to improve evaluation methods. To solve this problem, this study proposed a PL-UTASTAR method to sort the battery suppliers and select the best product. This method used the PLTSs to collect the fuzzy evaluation information of experts and determined the weights of criteria through the BWM. The results calculated by the PL-UTASTAR method can accurately partition the data, which makes the calculation results consistent with the personal preference of the DM. 
To distinguish our model from the previous UTA series methods, we mainly list the following characteristics. Compared with the traditional UTASTAR series method, the PL-UTASTAR method can deal with hesitant qualitative evaluation information of experts, so that the model calculated by the reference set can calculate the result more accurately. The PLTS used in the model can not only represent DM's hesitancy between multiple linguistic items, but also denote the different degrees of preferences. In addition, the importance of different criteria is different. Considering the weight of each criterion in the mind of experts, the BWM method was used to reduce the amount of calculation and get the weights between criteria more efficiently than the traditional AHP, especially when the number of criteria is large.

However, this method does not explain the treatment of different forms of information. The evaluation information of experts may be a combination of multiple expressions. It is necessary to explore the comprehensive expression forms of different evaluation information in the future. For example, we can integrate the qualitative subjective evaluation information with the quantitative number or interval fuzzy number, and use different ways of information expression under different criteria. This method deals with the problem of selecting battery suppliers, which will be interesting if the factor of time is taken into account. The question of how to deal with the impact of the factor of time on the weights of criteria will be explored. In the future, the PL-UTASTAR method can be promoted and expanded into other fields by integrating different evaluation information and taking into account of the factor of time.

In the future, the PL-UTASTAR method can be used in supplier selection in different industries. It can also be extended to the problem of scheme selection and sorting under different criteria. It is especially suitable for information processing with big data, which can be modelled by a small part of the data to process more data. For example, the PL-UTASTAR method can be used in regional location design scheme ranking and university comprehensive ranking. Besides, in the future, some variables with adjustable parameters can be introduced into the model, and sensitivity analysis can be carried out to study the influence of these variables on the model results. In general, the PL-UTASTAR method can process different forms of information and take the factor of time into account to comprehensively sort the schemes.

\section{Funding}

The work was supported by the National Natural Science Foundation of China (Grants No 71771156, 71971145).

\section{Author contributions}

Huchang Liao and Zhihang Liu conceived the study and were responsible for the design and development of the data analysis.
Huchang Liao, Zhihang Liu and Xiang Zhou were responsible for data collection and analysis.

Huchang Liao, Zhihang Liu and Xiang Zhou wrote the first draft of the paper.

Audrius Banaitis and Edmundas Kazimieras Zavadskas analysed data, checked and revise the draft.

\section{Disclosure statement}

The authors have no competing financial, professional, or personal interests from other parties that are related to this paper.

\section{References}

Alizadeh, R.; Majidpour, M.; Maknoon, R.; Kaleibari, S. S. 2016. Clean development mechanism in Iran: does it need a revival?, International Journal of Global Warming 10(1-3): 196215. https://doi.org/10.1504/IJGW.2016.077913

Alizadeh, R.; Majidpour, M.; Maknoon, R.; Salimi, J. 2015. Iranian energy and climate policies adaptation to the Kyoto protocol, International Journal of Environmental Research 9(3): 853-864. https://doi.org/10.22059/ijer.2015.972

Alizadeh, R.; Soltanisehat, L.; Lund, P. D.; Zamanisabzi, H. 2020. Improving renewable energy policy planning and decisionmaking through a hybrid MCDM method, Energy Policy 137: 111174. https://doi.org/10.1016/j.enpol.2019.111174

Asadabadi, M. R.; Chang, E.; Zwikael, O.; Saberi, M.; Sharpe, K. 2020. Hidden fuzzy information: Requirement specification and measurement of project provider performance using the best worst method, Fuzzy Sets and Systems 383: 127-145. https://doi.org/10.1016/j.fss.2019.06.017

Athawale, V. M.; Kumar, R.; Chakraborty, S. 2011. Decision making for material selection using the UTA method, The International Journal of Advanced Manufacturing Technology 57(1-4): 11. https://doi.org/10.1007/s00170-011-3293-7

Beiragh, R. G.; Alizadeh, R.; Kaleibari, S. S.; Cavallaro, F.; Hashemkhani Zolfani, S.; Bausys, R.; Mardani, A. 2020. An integrated multi-criteria decision making model for sustainability performance assessment for insurance companies, Sustainability 12(3): 789. https://doi.org/10.3390/su12030789

Carreno, M.; Ge, Y.-E.; Borthwick, S. 2014. Could green taxation measures help incentivise future Chinese car drivers to purchase low emission vehicles?, Transport 29(3): 260-268. https://doi.org/10.3846/16484142.2014.913261

Chen, K.; Zhao, F.; Hao, H.; Liu, Z. 2019. Selection of lithiumion battery technologies for electric vehicles under China's new energy vehicle credit regulation, Energy Procedia 158: 3038-3044. https://doi.org/10.1016/j.egypro.2019.01.987

Demesouka, O. E.; Anagnostopoulos, K. P.; Siskos, E. 2019. Spatial multicriteria decision support for robust land-use suitability: the case of landfill site selection in Northeastern Greece, European Journal of Operational Research 272(2): 574-586. https://doi.org/10.1016/j.ejor.2018.07.005

Diouf, B.; Pode, R. 2015. Potential of lithium-ion batteries in renewable energy, Renewable Energy 76: 375-380. https://doi.org/10.1016/j.renene.2014.11.058

Gong, H.; Wang, M. Q.; Wang, H. 2013. New energy vehicles in China: policies, demonstration, and progress, Mitigation and Adaptation Strategies for Global Change 18(2): 207-228. https://doi.org/10.1007/s11027-012-9358-6 
Grigoroudis, E.; Zopounidis, C. 2012. Developing an employee evaluation management system: the case of a healthcare organization, Operational Research 12(1): 83-106.

https://doi.org/10.1007/s12351-011-0103-9

Gruca, A.; Sikora, M. 2013. Rule based functional description of genes - estimation of the multicriteria rule interestingness measure by the UTA method, Biocybernetics and Biomedical Engineering 33(4): 222-234.

https://doi.org/10.1016/j.bbe.2013.09.005

Haider, H.; Singh, P.; Ali, W.; Tesfamariam, S.; Sadiq, R. 2015. Sustainability evaluation of surface water quality management options in developing countries: multicriteria analysis using fuzzy UTASTAR method, Water Resources Management 29(8): 2987-3013. https://doi.org/10.1007/s11269-015-0982-2

Hruška, R.; Průša, P.; Babić, D. 2014. The use of AHP method for selection of supplier, Transport 29(2): 195-203.

https://doi.org/10.3846/16484142.2014.930928

Ishizaka, A.; Resce, G. 2021. Best-worst PROMETHEE method for evaluating school performance in the OECD's PISA project, Socio-Economic Planning Sciences 73: 100799.

https://doi.org/10.1016/j.seps.2020.100799

Jacquet-Lagreze, E.; Siskos, J. 1982. Assessing a set of additive utility functions for multicriteria decision-making, the UTA method, European Journal of Operational Research 10(2): 151-164. https://doi.org/10.1016/0377-2217(82)90155-2

Jayant, A.; Chandan, A. K.; Singh, S. 2019. Sustainable supplier selection for battery manufacturing industry: a MOORA and WASPAS based approach, Journal of Physics: Conference Series 1240: 012015.

https://doi.org/10.1088/1742-6596/1240/1/012015

Kaleibari, S. S.; Beiragh, R. G.; Alizadeh, R.; Solimanpur, M. 2016. A framework for performance evaluation of energy supply chain by a compatible network data envelopment analysis model, Scientia Iranica: Transactions E: Industrial Engineering 23(4): 1904-1917. https://doi.org/10.24200/sci.2016.3936

Li, J.; Ku, Y.; Liu, C.; Zhou, Y. 2020. Dual credit policy: promoting new energy vehicles with battery recycling in a competitive environment?, Journal of Cleaner Production 243: 118456. https://doi.org/10.1016/j.jclepro.2019.118456

Li, L.; Jing, X. 2019. Analysis of tax policy for promoting the development of China's new energy vehicles industry, Advances in Social Science, Education and Humanities Research 328: 315-320. https://doi.org/10.2991/ichssd-19.2019.63

Liao, H.; Mi, X.; Xu, Z. 2020. A survey of decision-making methods with probabilistic linguistic information: bibliometrics, preliminaries, methodologies, applications and future directions, Fuzzy Optimization and Decision Making 19(1): 81-134. https://doi.org/10.1007/s10700-019-09309-5

Liao, H.; Xu, Z.; Herrera-Viedma, E.; Herrera, F. 2018. Hesitant fuzzy linguistic term set and its application in decision making: a state-of-the-art survey, International Journal of Fuzzy Systems 20(7): 2084-2110.

https://doi.org/10.1007/s40815-017-0432-9

Liu, Y.; Kokko, A. 2013. Who does what in China's new energy vehicle industry?, Energy Policy 57: 21-29. https://doi.org/10.1016/j.enpol.2012.05.046

Makui, A.; Momeni, M. 2012. Using CSW weight's in UTASTAR method, Decision Science Letters 1: 39-46. https://doi.org/10.5267/j.dsl.2012.06.001

Mi, X.; Liao, H.; Wu, X.; Xu, Z. 2020. Probabilistic linguistic information fusion: a survey on aggregation operators in terms of principles, definitions, classifications, applications, and challenges, International Journal of Intelligent Systems 35(3): 529-556. https://doi.org/10.1002/int.22216
Mi, X.; Tang, M.; Liao, H.; Shen, W.; Lev, B. 2019. The state-ofthe-art survey on integrations and applications of the best worst method in decision making: why, what, what for and what's next?, Omega 87: 205-225.

https://doi.org/10.1016/j.omega.2019.01.009

Nian, V.; Chou, S. K.; Su, B.; Bauly, J. 2014. Life cycle analysis on carbon emissions from power generation - the nuclear energy example, Applied Energy 118: 68-82.

https://doi.org/10.1016/j.apenergy.2013.12.015

Nikas, A.; Doukas, H.; Siskos, E.; Psarras, J. 2018. International cooperation for clean electricity: a UTASTAR application in energy policy, in N. Matsatsinis, E. Grigoroudis (Eds.). Preference Disaggregation in Multiple Criteria Decision Analysis. Multiple Criteria Decision Making, 163-186. https://doi.org/10.1007/978-3-319-90599-0_8

Pang, Q.; Wang, H.; Xu, Z. 2016. Probabilistic linguistic term sets in multi-attribute group decision making, Information Sciences 369: 128-143. https://doi.org/10.1016/j.ins.2016.06.021

Papapostolou, A.; Karakosta, C.; Nikas, A.; Psarras, J. 2017. Exploring opportunities and risks for RES-E deployment under cooperation mechanisms between EU and Western Balkans: a multi-criteria assessment, Renewable and Sustainable Energy Reviews 80: 519-530.

https://doi.org/10.1016/j.rser.2017.05.190

Patiniotakis, I.; Apostolou, D.; Mentzas, G. 2011. Fuzzy UTASTAR: a method for discovering utility functions from fuzzy data, Expert Systems with Applications 38(12): 15463-15474.

https://doi.org/10.1016/j.eswa.2011.06.014

Rezaei, J. 2015. Best-worst multi-criteria decision-making method, Omega 53: 49-57.

https://doi.org/10.1016/j.omega.2014.11.009

Saaty, T. L. 1977. A scaling method for priorities in hierarchical structures, Journal of Mathematical Psychology 15(3): 234281. https://doi.org/10.1016/0022-2496(77)90033-5

Sims, R. E. H.; Rogner, H.-H.; Gregory, K. 2003. Carbon emission and mitigation cost comparisons between fossil fuel, nuclear and renewable energy resources for electricity generation, Energy Policy 31(13): 1315-1326. https://doi.org/10.1016/S0301-4215(02)00192-1

Siskos, Y.; Yannacopoulos, D. 1985. UTASTAR: an ordinal regression method for building additive value functions, Investigação Operacional 5(1): 39-53.

Sola, A. V. H.; Mota, C. M. D. M. 2012. A multi-attribute decision model for portfolio selection aiming to replace technologies in industrial motor systems, Energy Conversion and Management 57: 97-106.

https://doi.org/10.1016/j.enconman.2011.12.013

Stević, Ž.; Vasiljević, M.; Puška, A.; Tanackov, I.; Junevičius, R.; Vesković, S. 2019. Evaluation of suppliers under uncertainty: a multiphase approach based on fuzzy AHP and fuzzy EDAS, Transport 34(1): 52-66. https://doi.org/10.3846/transport.2019.7275

Touni, Z.; Makui, A.; Mohammadi, E. 2019. A MCDM-based approach using UTA-STRAR method to discover behavioral aspects in stock selection problem, International Journal of Industrial Engineering \& Production Research 30(1): 93-103. https://doi.org/10.22068/ijiepr.30.1.93

Van de Kaa, G.; Rezaei, J.; Taebi, B.; Van de Poel, I.; Kizhakenath, A. 2020. How to weigh values in value sensitive design: a best worst method approach for the case of smart metering, Science and Engineering Ethics 26(1): 475-494. https://doi.org/10.1007/s11948-019-00105-3

Walter, B.; Pietrzak, B. 2005. Multi-criteria detection of bad smells in code with UTA method, Lecture Notes in Computer Science 3556: 154-161. https://doi.org/10.1007/11499053_18 
Whittington, H. W. 2002. Electricity generation: options for reduction in carbon emissions, Philosophical Transactions of the Royal Society A: Mathematical, Physical and Engineering Sciences 360(1797): 1653-1668.

https://doi.org/10.1098/rsta.2002.1025

Wu, X.; Liao, H.; Xu, Z.; Hafezalkotob, A.; Herrera, F. 2018. Probabilistic linguistic MULTIMOORA: a multicriteria decision making method based on the probabilistic linguistic expectation function and the improved Borda rule, IEEE Transactions on Fuzzy Systems 26(6): 3688-3702.

https://doi.org/10.1109/TFUZZ.2018.2843330

Xiong, W.-T.; Cheng, J. 2016. A weighted UTASTAR method for the multiple criteria decision making with interval numbers, Advances in Economics, Business and Management Research 10: 191-195. https://doi.org/10.2991/msmi-16.2016.46

Yuan, X.; Liu, X.; Zuo, J. 2015. The development of new energy vehicles for a sustainable future: a review, Renewable and Sustainable Energy Reviews 42: 298-305.

https://doi.org/10.1016/j.rser.2014.10.016

Yuan, H.; Jiang, Y. 2019. Research on key influencing factors of China's new energy automobile industry development, $A d$ vances in Economics, Business and Management Research 91: 676-681. https://doi.org/10.2991/edmi-19.2019.117

Zadeh, L. A. 1965. Fuzzy sets, Information and Control 8(3): 338-353. https://doi.org/10.1016/S0019-9958(65)90241-X

Zadeh, L. A. 1975. The concept of a linguistic variable and its application to approximate reasoning - I, Information Sciences 8(3): 199-249. https://doi.org/10.1016/0020-0255(75)90036-5

Zadeh, L. A. 2012. Computing with Words. Springer. 142 p. https://doi.org/10.1007/978-3-642-27473-2

Zhang, C.; Luo, L.; Liao, H.; Mardani, A.; Streimikiene, D.; Al-Barakati, A. 2020. A priority-based intuitionistic multiplicative UTASTAR method and its application in low-carbon tourism destination selection, Applied Soft Computing 88: 106026. https://doi.org/10.1016/j.asoc.2019.106026 